\title{
The Effect of Cellulose Overproduction on Binding and Biofilm Formation on Roots by Agrobacterium tumefaciens
}

\author{
Ann G. Matthysse, ${ }^{1}$ Mazz Marry, ${ }^{2}$ Leonard Krall, ${ }^{1}$ Mitchell Kaye, ${ }^{1}$ Bronwyn E. Ramey, ${ }^{3}$ Clay Fuqua, ${ }^{3}$ and \\ Alan R. White ${ }^{2}$ \\ ${ }^{1}$ University of North Carolina, Department of Biology, Chapel Hill 27599-3280, U.S.A.; ${ }^{2}$ North Dakota State University, \\ Department of Biological Sciences, Fargo 58105-5517, U.S.A.; ${ }^{3}$ Indiana University, Department of Biology, Bloomington \\ 47405, U.S.A.
}

Submitted 11 January 2005. Accepted 10 May 2005.

Agrobacterium tumefaciens growing in liquid attaches to the surface of tomato and Arabidopsis thaliana roots, forming a biofilm. The bacteria also colonize roots grown in sterile quartz sand. Attachment, root colonization, and biofilm formation all were markedly reduced in $\operatorname{cel} A$ and $\operatorname{chv} B \mathrm{mu}-$ tants, deficient in production of cellulose and cyclic $\beta-(1,2)$ D-glucans, respectively. We have identified two genes (celG and $(e l I)$ in which mutations result in the overproduction of cellulose as judged by chemical fractionation and methylation analysis. Wild-type and $\operatorname{chv} B$ mutant strains carrying a cDNA clone of a cellulose synthase gene from the marine urochordate Ciona savignyi also overproduced cellulose. The overproduction in a wild-type strain resulted in increased biofilm formation on roots, as evaluated by light microscopy, and levels of root colonization intermediate between those of cellulose-minus mutants and the wild type. Overproduction of cellulose by a nonattaching $\operatorname{chvB}$ mutant restored biofilm formation and bacterial attachment in microscopic and viable cell count assays and partially restored root colonization. Although attachment to plant surfaces was restored, overproduction of cellulose did not restore virulence in the $\operatorname{chvB}$ mutant strain, suggesting that simple bacterial binding to plant surfaces is not sufficient for pathogenesis.

Additional keyword: exopolysaccharide.

Agrobacterium tumefaciens is a gram-negative soil bacterium that infects wounds, causing the formation of crown gall tumors in most dicotyledonous plants. In addition to infecting wound sites, A. tumefaciens is also a proficient root colonizer, growing to large numbers (more than $10^{6}$ per centimeter of root length) on intact roots in soil or sterilized quartz sand (Matthysse and McMahan 1998). During the interaction of the bacteria with the plant surface, an unidentified plant substance stimulates the bacteria to synthesize cellulose fibrils, which aid in root colonization and tumor formation (Matthysse 1983; Matthysse et al. 1981). The-cellulose fibrils bind A. tumefaciens cells tightly to the plant surface and also to each other, forming large bacterial aggregates on the plant surface. A. tu-

Corresponding author: A. G. Matthysse; Telephone: (919)-962-6941; Fax: (919)-962-1625; E-mail: ann_matthysse@unc.edu

Present address of L. Krall: Metal Homeostasis Group, Max Planck Institute for Molecular Plant Physiology, Am Mühlenberg 1, 14476 Golm, Germany. mefaciens mutants that cannot make cellulose show reduced binding to plant surfaces in liquid media and can easily be removed by gentle water washing. Mutants deficient for cellulose production also are markedly reduced in their ability to colonize roots grown in quartz sand (Matthysse and McMahan 1998). The effects of overproduction of cellulose have been less well studied. One cellulose-overproducing A. tumefaciens mutant was reported to be virulent (Matthysse 1983). The effect of cellulose overproduction on bacterial binding, root colonization, and biofilm formation was not examined.

Microbial biofilms generally are defined as surface-associated, multicellular assemblages of organisms (Parsek and Fuqua 2004). The first step in biofilm formation is attachment of individual or small groups of bacteria to the surface. Attachment is followed by bacterial growth and additional attachment to form a biofilm. Large amounts of extracellular matrix material often are produced during biofilm formation. This matrix holds the cells in association with each other and the surface and commonly contains exopolysaccharides (EPS) such as cellulose (Sutherland 2001). Hyperadherent strains of Pseudomonas aeruginosa and Vibrio cholerae result from mutations that cause the overproduction of EPS. In the opportunistic human pathogen $P$. aeruginosa, mucoid derivatives with elevated synthesis of the EPS alginate may arise in the lungs of cystic fibrosis patients. These mucoid strains form dense biofilms on inert surfaces as well as human tissue and are highly virulent (Mathee et al. 1999). Although quite robust in general, the biofilms of mutant bacteria are structurally and physiologically distinct from wild-type $P$. aeruginosa biofilms (Hentzer et al. 2001). Similarly, hypermucoid strains of $V$. cholerae El Tor (known as rugose variants) overproduce Vibrio polysaccharide (VPS), form biofilms that are much thicker than the wild type, and demonstrate increased resistance to chlorine treatment (Yildiz and Schoolnik 1999). However, overproduction of EPS does not result in a hyperadherent phenotype in all biofilmforming bacteria (Parsek and Fuqua 2004).

In this study, we analyzed the effect of cellulose overproduction on attachment, biofilm formation, and colonization of roots by $A$. tumefaciens.

\section{RESULTS}

Attachment and biofilm formation on roots by wild-type $A$. tumefaciens.

Attachment of $A$. tumefaciens to roots was examined under two conditions. The first used microscopic studies of bacte- 
rial attachment and biofilm formation in the presence of excess bacteria and limiting plant surface. The second measured bacterial attachment in the presence of excess plant surface. In both cases, plant root segments were present at between 1 and $2 \mathrm{~cm}$ of root length per milliliter. When inoculated at high density on tomato roots, A. tumefaciens C58 formed a biofilm as visualized in the light microscope (Fig. 1). The bacteria bound first as individual cells and small clusters on the epidermis and longer root hairs (Fig. 1A to C). By $7 \mathrm{~h}$, large clusters of $A$. tumefaciens were visible on both the epidermis and longer root hairs (Fig. 1D to F). After $31 \mathrm{~h}$, the surface of the roots was covered with bacteria, which formed large clusters on the epidermis and on both long and short root hairs. Streamers of bacteria connected the root hairs to each other and formed an open lattice over the root surface with channels between the clusters of bacteria (Fig. 1G to I). Similar results were obtained when A. tumefaciens C58 was incubated with the roots of other plants, including alfalfa and Arabidopsis thaliana (data not shown).

Binding of C58 to roots inoculated with low numbers of bacteria (i.e., excess plant surface area for colonization) was examined using a viable cell count assay (discussed below). Approximately $20 \%$ of the bacterial inoculum was bound to the surface of tomato roots after $2 \mathrm{~h}$ of incubation (Table 1 ). When roots inoculated with low numbers of bacteria were examined in the microscope after $48 \mathrm{~h}$, bacterial biofilm formation was similar in appearance to that seen with high numbers of bacteria after $31 \mathrm{~h}$ (data not shown).
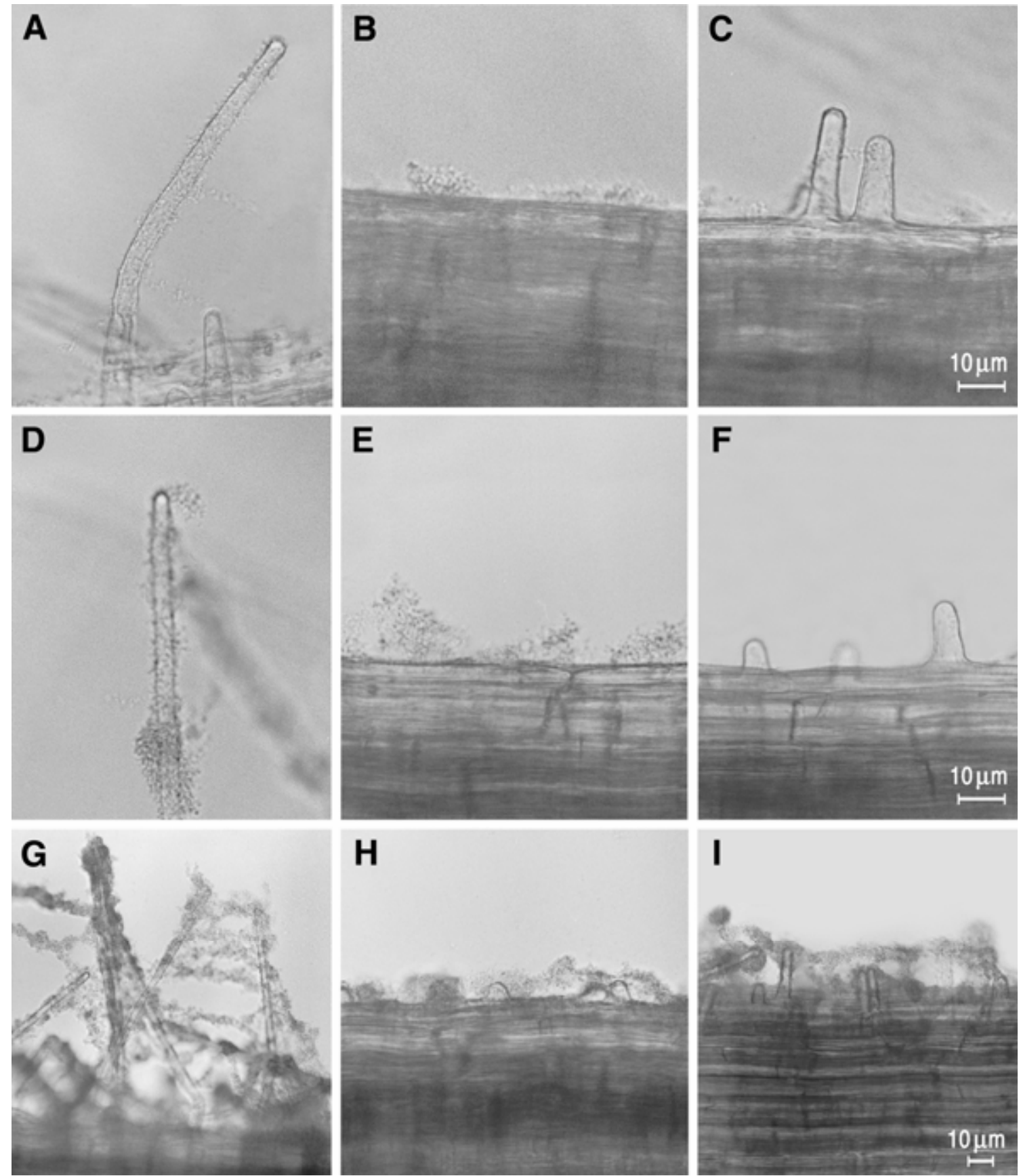

Fig. 1. Time course of the formation of a biofilm on the surface of a tomato root by wild-type strain C58; A, B, and $\mathbf{C}, 3$ h; D, E, and F, 7 h; G, H, and I, 31 h. A, D, and G, Long root hairs; B, E, and $\mathbf{H}$, epidermis; C, F, and I, short root hairs. Bacteria bind first to long root hairs and epidermis. By 7 h, aggregates have formed on these surfaces while a few individual bacteria are bound to the short root hairs. After $31 \mathrm{~h}$, all the root surfaces are covered with bacterial aggregates. The presence of the root hairs adds structure to this biofilm not seen on smooth surfaces. 


\section{Identification of celI and celG.}

A cellulose-overproducing Tn5 mutant of Agrobacterium tumefaciens octopine-type strain A6, designated B1, was described previously (Matthysse 1983). In order to identify the gene, a BamHI fragment containing one end of the transposon with the nptII gene and adjacent $A$. tumefaciens DNA was sequenced. The insertion was in a gene identical to AGR_L_3407p in the genome sequence of the nopaline-type A. tumefaciens strain C58 (accession number NC_003063). The amino acid sequence encoded by the gene, which we named cell (cellulose synthesis inhibitor), has homology to COG4189 with an $E$ value of $2 \mathrm{e}^{-123}$. Gene celI appears to be a member of the MarR/ArsR gene family of transcriptional regulators and is located on the linear chromosome, as are the cellulose synthesis genes, but is not adjacent to the cellulose synthase structural genes. Some genes in the immediate vicinity of celI appear to be involved with sugar uptake and metabolism. Whether the cell gene is monocistronic or part of a larger operon is unknown.
The gene upstream of celI (AGR_L_3404) is transcribed in the same direction as celI (Fig. 2A), and a gap of $194 \mathrm{bp}$ is present between the two genes. An 11-bp inverted repeat is located 16 bp after the end of AGR_L_3404, followed by a T-rich region, which may represent a transcription termination site. The genes following celI are oriented in the same direction as celI. There is a gap of 121 bp between cell and the adjacent gene, AGR_L_3408, which has a ribosome binding site 8 bp upstream of the ATG start codon. A possible promoter is located in the 121-bp gap between these genes (Fig. 2A). Whether cell has any relationship to the neighboring genes is unknown.

Examination of the C58 genomic sequence revealed a previously undescribed open reading frame (AGR_L_3028p) located between celC and celE oriented in the same direction as celC (Fig. 2B). The predicted protein product of the gene, which was named celG, has homology to hypothetical proteins from Magnetospirillum magnetotacticum and Rhodobacter sphaeroides.

Table 1. Interactions of Agrobacterium tumefaciens wild-type and mutant strains with tomato roots

\begin{tabular}{|c|c|c|c|c|}
\hline \multirow[b]{2}{*}{ Bacterial strain } & \multicolumn{2}{|c|}{ Root attachment } & \multirow[b]{2}{*}{ Colonization $^{c}$} & \multirow[b]{2}{*}{ Virulence $^{d}$} \\
\hline & Observation at $24 \mathrm{~h}^{\mathrm{a}}$ & $\%$ Inoculum bound after $2 \mathrm{~h}^{\mathrm{b}}$ & & \\
\hline C58 & +++ & $20 \pm 3$ & $6.0 \pm 0.4$ & $40 / 40$ \\
\hline C58CelA & \pm & $5 \pm 5$ & $2.0 \pm 0.5$ & $0 / 20$ \\
\hline C58CelG & ++++ & $26 \pm 5$ & $4.8 \pm 0.5$ & $20 / 20$ \\
\hline C58CelI & ++++ & $23 \pm 6$ & $4.4 \pm 0.2$ & $20 / 20$ \\
\hline C58ChvB & - & $1 \pm 1$ & $4.4 \pm 0.5$ & $0 / 20$ \\
\hline C58ChvBCelG & +++ & $27 \pm 5$ & $5.7 \pm 0.4$ & $0 / 20$ \\
\hline C58ChvBCelI & +++ & $18 \pm 5$ & $5.4 \pm 0.3$ & $0 / 20$ \\
\hline C58ChvBCelACelI & \pm & $1 \pm 1$ & $4.0 \pm 0.2$ & $0 / 20$ \\
\hline C58ChvB pTE3 & \pm & $3 \pm 3$ & $4.5 \pm 0.3$ & $0 / 15$ \\
\hline C58ChvB pTE3TL17 & +++ & $25 \pm 4$ & $5.0 \pm 0.2$ & $0 / 15$ \\
\hline
\end{tabular}

${ }^{\text {a }}$ Microscopic observation; $-=$ no attachment, $\pm=$ less than 10 bacteria attached per 0.1 mm of root, $+++=$ root surface almost covered with attached bacteria, and $++++=$ root surface covered with a layer of bacteria several cells deep.

${ }^{\mathrm{b}}$ Inoculum bound; mean \pm standard deviation.

${ }^{\mathrm{c}}$ Root colonization (log mean number bound per centimeter of root length after 7 days; mean \pm standard deviation.

${ }^{\mathrm{d}}$ Virulence on Bryophyllum daigremontiana; number of sites forming tumors/number of sites inoculated. At least three different plants were inoculated at different times.

\section{A cell and adjacent genes}

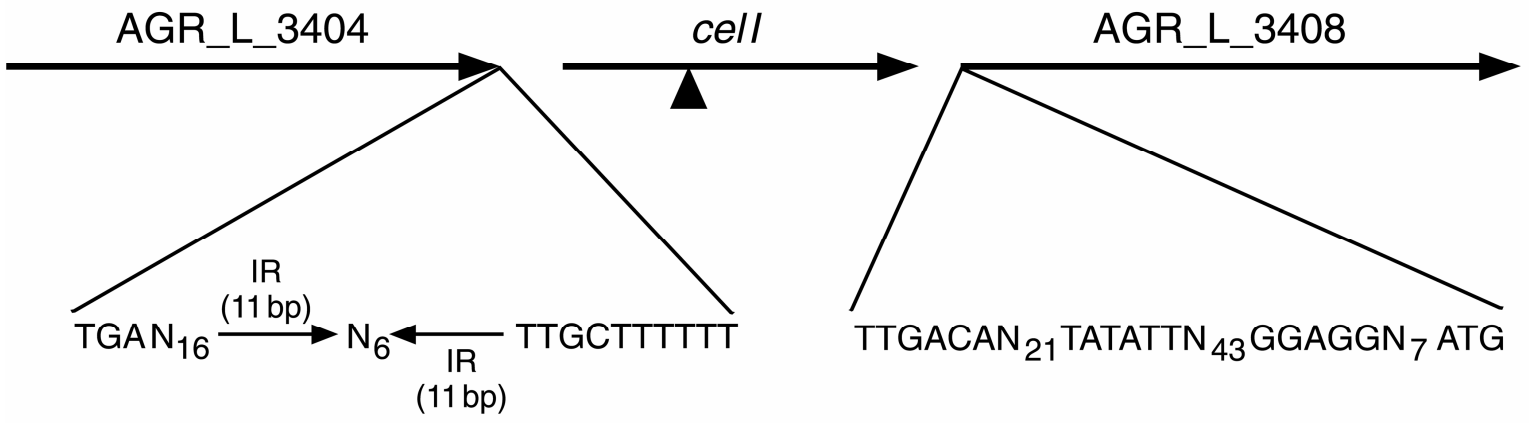

\section{B Genes of the cellulose synthesis region}

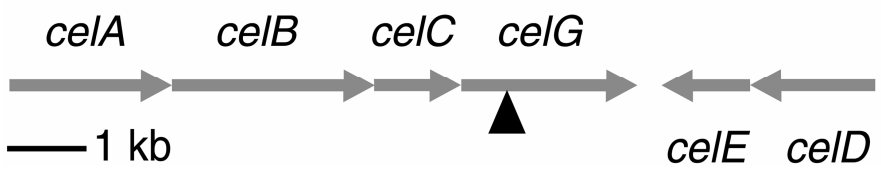

Fig. 2. Map of the genes involved in the regulation and production of cellulose; $\mathbf{A}$, cell and neighboring genes; B, cellulose synthesis genes and celG. Sequences are from the Cereon sequence of the Agrobacterium tumefaciens C58 complete genome (NCBI accession number NC_003063). All of the genes shown are on the linear chromosome. 


\section{Cellulose production by celG and celI mutants.}

Mutations in cell and celG were created in various chromosomal backgrounds by interrupting the gene by insertion of a plasmid carrying an internal fragment of the gene (Fig. 2; Table 2 ; discussed below). Cellulose overproduction then was examined in the wild-type C58 strain, and a nonattaching mutant of $\mathrm{C} 58$ (ChvB). The $\operatorname{chvB}$ mutants lack the enzyme for incorporation of UDP-glucose into $\beta-(1,2)-D-$ glucan (Puvanesarajah et al. 1985). UDP-glucose also is the precursor for cellulose. Extracts of wild-type A. tumefaciens incorporate UDP-glucose into $\beta$-(1,2)-D-glucan so that its synthesis interferes with measurements of cellulose biosynthesis in vitro (Matthysse et al. $1995 \mathrm{~b}$ ). Therefore, all in vitro measurements of cellulose synthesis have been made in strains with a $\operatorname{chvB}$ mutation. When compared with the parent strain, celI and celG mutants in both the C58 and C58ChvB backgrounds formed large aggregates of bacteria when grown in liquid (discussed below). Cellulose synthesis by extracts of $A$. tumefaciens C58ChvB is increased by the addition of $0.02 \%$ soytone (Matthysse et al. 1995b). Extracts of C58ChvB grown in Luria broth do not incorporate detectable amounts of UDP- ${ }^{14} \mathrm{C}$-glucose into cellulose. Extracts of both the double mutants $(\operatorname{chvB}$, celI and $\operatorname{chvB}$, celG) grown in Luria broth were able to synthesize detectable amounts of cellulose. However, cellulose synthesis by extracts of the C58ChvB, C58ChvBCelI, and C58ChvBCelG strains was increased when the bacteria were grown in Luria broth with soy- tone (Table 3 ). The results suggest that these mutations do not affect the response of the bacteria to soytone. Cellulose synthesis by the overproducing mutant strains (C58ChvBCelI and C58ChvBCelG) was reduced to (or below) the level of the parent strain when the mutations were complemented by the presence of a plasmid carrying the cell or celG gene expressed from the lac promoter (Table 3). Extracts of the C58ChvBCelA strain, which lacks cellulose synthase, showed no detectable cellulose synthesis regardless of the medium in which they were grown.

The chemical composition of washed and dried cell pellets of the C58ChvB, C58ChvBCelG, and C58ChvBCelI strains was examined. The pellets were derivatized for glycosyl linkage analysis and separated by gas chromatography mass spectrometry (GC-MS) into the resulting partially methylated alditol acetates (PMAA) to deduce the glycosyl linkages present. The C58ChvB strain contained a smaller amount of glucose than either the C58ChvBCelG or C58ChvBCelI strains (Table 4). Of the total amount of glucose detected, the ChvB mutant and the two double mutants contained the same proportion of terminally linked glucosyl residues $(3.8 \mathrm{~mol} \% \pm 4 \mathrm{~mol} \%)$, indicating that the polysaccharides had similar chain lengths. The C58ChvBCelI and C58ChvBCelG strains contained a higher proportion of four-linked glucosyl residues than the C58ChvB strain, whereas all three strains contained the same proportion of three-linked glucosyl residues $(6 \mathrm{~mol} \% \pm 4 \mathrm{~mol} \%)$. No six-

Table 2. Agrobacterium tumefaciens strains used in this study

\begin{tabular}{|c|c|c|}
\hline Bacterial strain & Relevant properties and genes & Source, reference \\
\hline C58 & Wild-type rif ${ }^{r}$ & Laboratory collection \\
\hline C58CelA & $\operatorname{celA}^{-}$carb $^{\mathrm{r}}$ & Laboratory collection \\
\hline C58CelG & celG $^{-}$carb $^{\mathrm{r}}$ & This study \\
\hline C58CelI & celI $^{-}$carb $^{\mathrm{r}}$ & This study \\
\hline C58ChvB & C58 $\operatorname{chvB}:: \operatorname{Tn} 5$ neo $^{\mathrm{r}}$ & A1045, Douglas et al. 1982 \\
\hline C58ChvBCelA & C58 chvB::Tn5 celA- carb $^{\mathrm{r}}$ & This study \\
\hline C58ChvBCelG & C58 chvB::Tn5 celG ${ }^{-}$carb $^{\mathrm{r}}$ & This study \\
\hline C58ChvBCelI & C58 chvB ::Tn5 celI ${ }^{-}$carb $^{\mathrm{r}}$ & This study \\
\hline C58ChvBCelACelI & C58 chvB ::Tn5 celA ${ }^{-} \operatorname{carb}^{\mathrm{r}}$ cell $^{-} \mathrm{cm}^{\mathrm{r}}$ & This study \\
\hline C58ChvB pTE3 & C58 $\operatorname{chvB}::$ Tn 5 , plasmid carries tet ${ }^{\mathrm{r}}$ & Matthysse et al. 2004 \\
\hline C58ChvB pTE3TL17 & C58 chvB::Tn5, plasmid pTE3 with the Ciona savignyi cellulose synthase cDNA & Matthysse et al. 2004 \\
\hline C58ChvBCell pBBRcelI & C58 chvB::Tn5 celI ${ }^{-}$carb $^{\mathrm{r}}$, plasmid carries gent ${ }^{\mathrm{r}}$ and $c e l I$ & This study \\
\hline C58ChvBCelG pBBRcelG & C58 chvB::Tn5 celG ${ }^{-}$carb $^{\mathrm{r}}$, plasmid carries gent $^{\mathrm{r}}$ and $c e l G$ & This study \\
\hline
\end{tabular}

Table 3. Cellulose synthesis by extracts of Agrobacterium tumefaciens cells

\begin{tabular}{|c|c|c|}
\hline \multirow[b]{2}{*}{ Bacterial strain } & \multicolumn{2}{|c|}{ Picomoles of UDP- ${ }^{14} \mathrm{C}$-glucose incorporated/min/extract of $10^{8}$ cells grown in ${ }^{\mathrm{a}}$} \\
\hline & Luria broth & Luria broth with $0.02 \%$ soytone \\
\hline C58ChvB & ND & $3 \pm 0.1$ \\
\hline C58ChvBCelI & $1.1 \pm 0.2$ & $6 \pm 0.4$ \\
\hline C58ChvBCelG & $1.6 \pm 0.2$ & $7.5 \pm 0.3$ \\
\hline C58ChvBCelA & ND & ND \\
\hline C58ChvBCelI pBBRcelI & ND & $1 \pm 0.5$ \\
\hline C58ChvBCelG pBBRcelG & ND & ND \\
\hline
\end{tabular}

${ }^{\mathrm{a}} \mathrm{ND}=$ not detected $(0.5$ picomole could have been detected $) ;$ mean \pm standard deviation.

Table 4. Cellulose content of wild-type and mutant strains ${ }^{\mathrm{a}}$

\begin{tabular}{|c|c|c|c|c|}
\hline \multirow[b]{2}{*}{ Bacterial strain } & \multirow[b]{2}{*}{ Cellulose $\left(\mathrm{mg} / 10^{10}\right.$ cells $)$} & \multicolumn{3}{|c|}{ Total polysaccharides (\%) } \\
\hline & & Glucose & Four-linked glucosyl residues & Three-linked glucosyl residues \\
\hline C58 & $2.2 \pm 0.3$ & NM & NM & NM \\
\hline C58Cell & $5.7 \pm 0.6$ & NM & NM & NM \\
\hline C58CelG & $11.1 \pm 0.9$ & NM & NM & NM \\
\hline C58CelA & $0.03 \pm 0.05$ & NM & NM & NM \\
\hline C58ChvB & $5.5 \pm 0.5$ & $42 \pm 8$ & $32 \pm 2$ & $6 \pm 4$ \\
\hline C58ChvBCelI & $10.0 \pm 0.2$ & $60 \pm 6$ & $50 \pm 4$ & $6 \pm 4$ \\
\hline C58ChvBCelG & $14.0 \pm 0.2$ & $58 \pm 4$ & $48 \pm 5$ & $6 \pm 4$ \\
\hline C58ChvBCelA & $0.01 \pm 0.05$ & NM & NM & NM \\
\hline
\end{tabular}

${ }^{a}$ Mean \pm standard deviation of a minimum of three independent measurements; $\mathrm{NM}=$ not measured. 
linked glucosyl residues were detected. Because cellulose is made up of linear chains of $\beta$-1,4-linked glucose, the results are consistent with cellulose overproduction by the $\mathrm{cel} G$ and cell mutants.

The total amount of cellulose also was determined by chemical purification from dried cell pellets. In both the C58 and C58ChvB backgrounds, the CelI and CelG mutants contained more cellulose per bacterial cell than did the parent strain (Table 4).

The phenotypes of insertions in celI and celG do not appear to be polar effects on downstream genes because, when either gene was cloned on a low-copy-number plasmid behind the lac promoter and introduced into the corresponding insertion mutant, the resultant strain no longer overproduced cellulose (Table 3). Thus, the phenotype of the insertion mutants appears to be due to the lack of the respective gene products.

\section{Attachment of cellulose synthesis mutants to roots.}

Bacterial binding to a surface is the first step in the formation of a bacterial biofilm on that surface. The effect of mutations in cellulose synthesis on A. tumefaciens binding to roots was examined using both microscopic and viable cell count assays. As previously reported, cellulose-minus mutants failed to show detectable binding to roots using either assay (Table 1) (Matthysse 1983). Cellulose-overproducing mutants showed no significant difference from wild-type bacteria in binding to root tissue after $2 \mathrm{~h}$ as measured using the viable cell count assay. However, when examined after $24 \mathrm{~h}$ in the light microscope, C58CelI and C58CelG typically showed larger bacterial aggregates on the root hairs and the biofilms formed on the epidermis were thicker than those seen with the wild-type par- ent (Fig. 3). These aggregates and biofilms were fragile and relatively easily dislodged by shaking or mixing (such as that performed during sample processing in the viable cell count assay). Thus, many of the bacteria in these large aggregates would be counted as free bacteria in the viable cell count assay of attachment.

The effect of cellulose overproduction in a bacterial mutant unable to attach to roots was examined. A. tumefaciens $\operatorname{chvB}$ mutants failed to show detectable binding to tomato roots with either the viable cell count or microscopic assay and failed to form a biofilm on the roots (Table 1; Fig. 4A). The double mutants C58ChvBCelI and C58ChvBCelG recovered the ability to bind to tomato and A. thaliana roots and to form a biofilm as measured with both attachment assays (Table 1; Fig. 4B). When a plasmid carrying the cloned cell or celG gene expressed from the lac promoter was introduced into the double mutants, they no longer overproduced cellulose (Table 3 ) and no longer bound to tomato roots using either the viable cell count or microscopic assays (no bound bacteria were observed). Seven-day root colonization assays were not conducted due to the instability of the plasmid in the absence of antibiotic selection. In order to determine whether the rescued attachment phenotype of the cell mutation was due to its effect on cellulose synthesis, a triple mutant, C58ChvBCelICelA, was constructed. This mutant cannot overproduce cellulose due to lack of a functional cellulose synthase gene. The phenotype of the triple mutant was the same as the C58ChvB single mutant; it showed no detectable binding to roots and reduced root colonization (Table 1; Fig. 4C). This result suggests that, indeed, the phenotype of the C58ChvBCelI double mutant was due to the overproduction of cellulose by the double mutant.
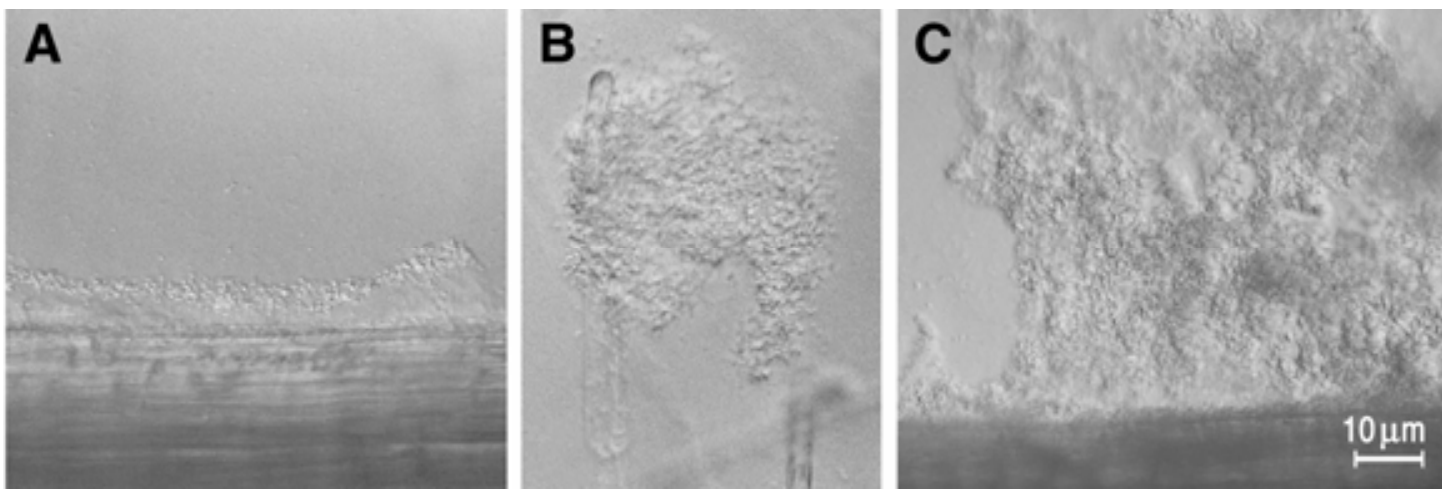

Fig. 3. Photomicrographs showing the binding of A, wild-type C58 and $\mathbf{B}$ and $\mathbf{C}, \mathrm{C} 58 \mathrm{Cell}$ to the tomato $\mathbf{A}$ and $\mathbf{C}$, root epidermis and $\mathbf{B}$, root hairs after $24 \mathrm{~h}$. Note $\mathbf{B}$, the very large aggregates seen on root hairs and $\mathbf{C}$, the deep biofilm on the epidermis formed by C58CelI.
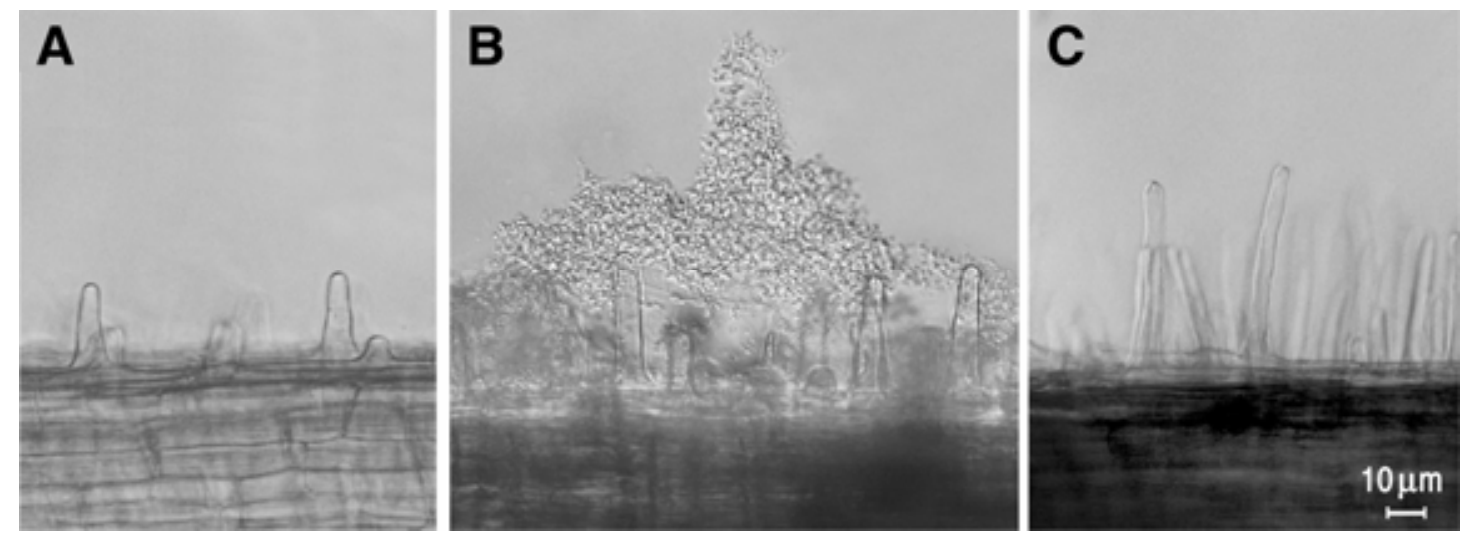

Fig. 4. Photomicrographs showing roots incubated with A, C58ChvB, B, C58ChvBCelI, and C, C58ChvBCelACelI. C58ChvB failed to show detectable binding to the root surface. Large numbers of the cellulose-overproducing mutant C58ChvBCelI bound to the root. The C58ChvBCelACelI mutant that cannot make cellulose showed the absence of binding seen with the C58ChvB parent strain. 
A second method was used to test the effect of cellulose overproduction on the ChvB mutant. A cDNA clone of the cellulose synthase gene from the tunicate Ciona savignyi has been shown to complement the cellulose synthesis defect in a CelA (cellulose synthase) mutant of A. tumefaciens. The introduction of this cDNA clone into the C58ChvB mutant causes overproduction of cellulose (Matthysse et al. 2004). When the interaction of the $\mathrm{C} 58 \mathrm{ChvB}$ mutant carrying this cDNA clone with roots was examined, we observed that it restored the ability of the C58ChvB mutant to bind to roots and to form a biofilm (Table 1).

\section{Root colonization.}

Bacterial colonization of roots growing in sterile quartz sand represents the formation of a bacterial biofilm on the root surface under conditions which are closer to those found in nature than biofilm formation on roots growing in liquid in a petri dish. Wild-type A. tumefaciens C58 was able to colonize tomato roots, reaching a density of approximately $10^{6}$ bacteria per centimeter of root length (Fig. 5). As reported previously, celluloseminus mutants are markedly reduced in their ability to colonize roots, reaching a density of $10^{2}$ bacteria per centimeter of root length in the same assays (Matthysse and McMahan 1998). The ability of the cellulose-overproducing mutants to colonize tomato roots was intermediate between that of the wild-type and the cellulose-minus bacteria, with bacterial numbers of approximately $10^{4}$ bacteria per centimeter of root length after 7 days of incubation (Fig. 5). Root colonization by the C58ChvB mutant was greater than that by C58CelA mutants but still significantly reduced when compared with that of wild-type bacteria (Table 1; Fig. 6). Root colonization by the double mutants C58ChvBCelI or C58ChvBCelG was restored to almost the same level as that of wild-type cells. Overproduction of cellulose by C58ChvB carrying a tunicate cellulose synthase gene also increased root colonization, although less than the double mutants. This may be due to loss of the plasmid during the 7 day growth period. Root colonization by the triple mutant that is unable to make cellulose was not significantly different from that of the parent C58ChvB mutant strain.

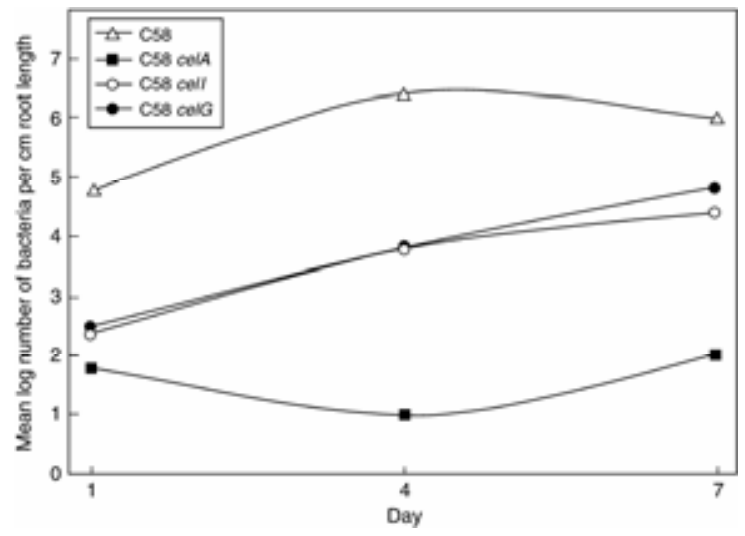

Fig. 5. Effect of mutations that alter the amount of cellulose produced on tomato root colonization by C58. Wild-type strain C58 colonized tomato roots, reaching population densities of approximately $10^{6}$ bacte$\mathrm{ria} / \mathrm{cm}$ of root length. The cellulose-minus mutant C58CelA colonized tomato roots very poorly, reaching a maximum population of only $10^{2}$ bacteria/cm of root length. The cellulose-overproducing mutants C58CelI and C58CelG showed a level of root colonization intermediate between that seen with the parent and the cellulose-minus mutant, suggesting that the amount of cellulose made by the wild-type strain is optimal for root colonization. The numbers shown are the mean of a minimum of three independent experiments. The standard deviation of all of the numbers was less than 0.5 .

\section{Virulence.}

The virulence of the C58CelG and C58CelI strains was unaltered. All of the sites inoculated with these mutants formed normal-sized tumors at roughly the same time as C58. Although the celG and celI mutations and the presence of the plasmid pTE3TL17 restored binding of C58ChvB mutant bacteria to root surfaces and to wound sites as visualized in the light microscope (Fig. 4), they did not restore virulence to this mutant (Table 1).

\section{DISCUSSION}

Two A. tumefaciens genes in which insertions resulted in the overproduction of cellulose were identified. The predicted protein product of cell has homology to DNA-binding regulatory proteins, whereas the predicted product of celG has homology only to hypothetical proteins. The simplest possible mechanism for the action of cell is that this gene encodes a repressor of the cellulose synthesis operon $($ celABC) and insertions in celI would increase expression of the genes required for cellulose synthesis. However, other mechanisms of action, including more complicated regulatory hierarchies and effects on the availability of cellulose precursors, also are possible. The mechanism by which a mutation in $\mathrm{cel} G$ increases cellulose synthesis is unclear.

When a low-copy-number plasmid carrying the cell or celG gene behind the lac promoter was introduced into the celI or celG mutants, respectively, the resulting bacteria no longer overproduced cellulose. As might be expected with the introduction of multiple copies of a gene that inhibits cellulose production, the complemented strains produced less cellulose than the parent strain. These results suggest that the effect of the insertion mutations in cell and celG on cellulose synthesis is due to the disruption of the genes themselves and not to polar effects on other genes.

The involvement of cellulose in bacterial biofilms has long been known for Acetobacter xylinum, which forms a biofilm at air-water interfaces and on the surface of decaying fruit (Cannon and Anderson 1991). More recently, cellulose has been observed to be involved in biofilm formation by $E s$ cherichia coli, Salmonella enteriditis, and S. typhimurium (White et al. 2003; Zogaj et al. 2001). P. fluorescens forms a

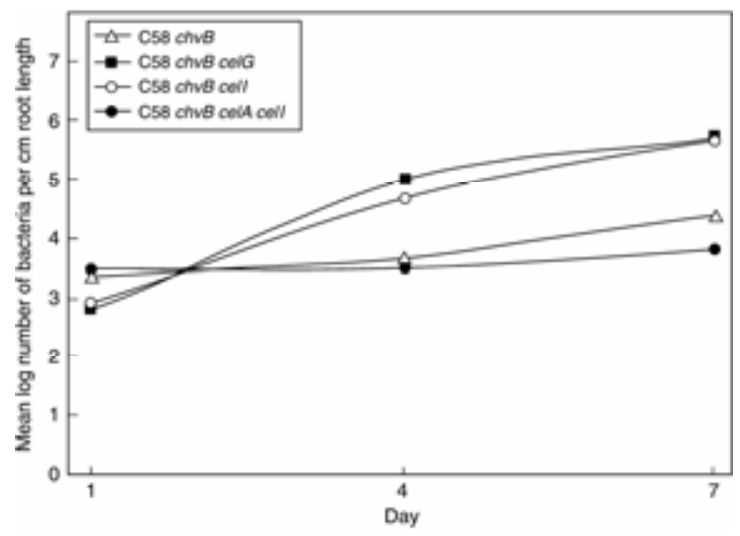

Fig. 6. Effect of mutations that alter the amount of cellulose produced on tomato root colonization by $\mathrm{C} 58 \mathrm{ChvB}$. Tomato root colonization by $\mathrm{C} 58 \mathrm{ChvB}$ was moderate, reaching populations of approximately $5 \times 10^{3}$ bacteria/cm of root length. The cellulose-overproducing mutants C58ChvBCelG and C58ChvBCelI showed increased root colonization, reaching $5 \times 10^{5}$ bacteria/cm of root length. The cellulose-minus triple mutant was not significantly different from the parent $\mathrm{C} 58 \mathrm{ChvB}$ strain. The numbers shown are the mean of a minimum of three independent experiments. The standard deviation of all of the numbers was less than 0.5 . 
biofilm containing acetylated cellulose (Spiers et al. 2003). Previous studies have shown that the absence of cellulose reduces the ability of Agrobacterium tumefaciens to bind to plant surfaces and to colonize roots and severely attenuates or eliminates virulence (Matthysse 1983; Matthysse and McMahan 1998; Minnemeyer et al. 1991). Mutants of P. fluorescens and $S$. enteriditis that are unable to make cellulose also fail to form a biofilm (Spiers et al. 2003; White et al. 2003). The effects of cellulose overproduction on these biofilms have not been examined. Overproduction of cellulose by A. tumefaciens resulted in a loosely bound, extensive biofilm on plant surfaces as visualized in the light microscope. However, these biofilms were so poorly attached to the substrate that they did not survive washing.

Although biofilm formation increased, the overproduction of cellulose reduced root colonization. The number of bacteria found growing on a root surface 4 to 7 days after inoculation is a result of the binding of the bacteria to the root, subsequent bacterial growth, and spread along the root surface. Bacteria that overproduce cellulose bound to roots and formed thick biofilms. However, their growth rate under these circumstances appeared to be slower than that of the wild-type strain, reducing the number of bacteria recovered from the roots. In general, bacteria which overproduced cellulose may be slightly retarded in growth. In liquid culture, C58 had a doubling time of $2.1 \mathrm{~h}$ compared with $2.5 \mathrm{~h}$ for the cellulose-overproducing mutant C58CelI (data not shown).

Bacteria that were unable to produce cellulose failed to bind well to the root and showed very low root colonization. The amount of cellulose produced by wild-type A. tumefaciens appears to represent a balance between root binding and the energy and growth cost of cellulose production.

The $\operatorname{chvB}$ mutants fail to bind plant cells, are altered in polysaccharide synthesis, and are avirulent. These mutants are unable to make $\beta$-(1,2)-D-glucan, an oligosaccharide that ordinarily is found in the periplasmic space in A. tumefaciens (Douglas et al. 1982). Although $c h v B$ mutants colonize roots poorly, this defect was partially complemented by cellulose overproduction, which increased their ability to attach to, and colonize, roots. However, cellulose overproduction did not restore virulence on Bryophyllum daigremontiana. The data provide support for a model that the binding to the plant surface required for bacterial virulence (tumor formation) is a specific type of binding and not all types of binding to plant tissues are adequate to support virulence.

\section{MATERIALS AND METHODS}

\section{Bacterial strains and growth.}

Wild-type virulent $A$. tumefaciens $\mathrm{C} 58$ and mutants derived from it were grown in Luria broth or on Luria agar at $25^{\circ} \mathrm{C}$ for all assays. In some cases, as noted, the Luria broth or agar was supplemented with $0.02 \%$ soytone. Cellulose-overproducing mutants were maintained on Luria agar with appropriate antibiotics and only colonies that appeared rough and sticky were transferred. Antibiotics were added to the medium at the following concentrations: carbenicillin at $50 \mathrm{mg} / \mathrm{liter}$, chloramphenicol at $30 \mathrm{mg} / \mathrm{liter}$, rifampicin at $50 \mathrm{mg} / \mathrm{liter}$, tetracycline at $10 \mathrm{mg} / \mathrm{ml}$, and neomycin at $60 \mathrm{mg} / \mathrm{liter}$ for solid media and $20 \mathrm{mg} / \mathrm{liter}$ for liquid media. The cellulose-minus strains C58CelA and C58ChvBCelA have been described previously (Matthysse et al. 1995a), as has the ChvB mutant A1045 (Douglas et al. 1982). The plasmid pTE3TL17 carrying a cDNA clone of the $C$. savignyi cellulose synthase gene also has been described previously (Matthysse et al. 2004).

The cellulose-overproducing mutant B1 contains a Tn5 insertion in the cell gene of A. tumefaciens strain A6 and has been described previously (Matthysse 1983). In order to study mutations in the cell gene in the C58 background, a 311-bp fragment of the gene was amplified from C58 using the following polymerase chain reaction (PCR) primers designed based on the C58 genome sequence: 5'-CGTAGA GCTCCAGCTTCCAACTCTATCGCAGTGGC-3' and 5'-GC TCTAGACGTTCACGGACAGCGTGATATCG-3'. Italics indicate restriction sites $S a c \mathrm{I}$ and $\mathrm{XbaI}$ used in cloning. The resulting DNA fragment was cloned into the pBluescript ampicillin-resistant and pBluescript chloramphenicol-resistant vectors. The entire plasmid was introduced into spontaneous, rifampicin-resistant mutants of A. tumefaciens C58, $\mathrm{C} 58 \mathrm{ChvB}$, and $\mathrm{C} 58 \mathrm{ChvBCelA}$ by triparental conjugation using pRK2013 as a mobilizing plasmid. Recombinants were selected on the appropriate antibiotics: rifampicin and carbenicillin for $\mathrm{C} 58$, neomycin and carbenicillin for $\mathrm{C} 58 \mathrm{ChvB}$, and chloramphenicol and carbenicillin for C58ChvBCelA. The presence of the plasmid integrated into the celI gene was confirmed by PCR using primers from the plasmid and a primer from the surrounding A. tumefaciens chromosomal DNA.

Mutations in celG were constructed in strains C58 and C58ChvB, using the same method as that described for cell. The PCR primers used for celG were 5'-CGTAGAGCTCCATT GGCATGCTCTCGCTTGCC-3' and 5'-GTCTAGAGCGCCAG ACCCTGCGAGGC-3' to amplify a 593-bp fragment of the gene. Italics indicate restriction sites $S a c I$ and $X b a I$ used in cloning. Figure 2 contains a map showing the locations of the plasmid insertions.

The complete open reading frames of cell and celG were amplified using PCR and the following primers: CGCGTCGA CAAGCTTATGGCGCCCAATTTC and GGACGTCTAGATC AATATCCGCAAGCG (cell) and CGAGCCTCGAGATGCCG ATGAATAAGCCACTGTCG and CGTCTAGAGCTGTCAGC CACCGCCCTGAG (celG). (Italics indicate the SalI, XbaI, and $X h o I$ sites used in cloning). The genes were cloned into the SalI and XbaI (celI) and XhoI and XbaI (celG) sites of pBBRmcs-5 and the resulting plasmids were introduced into C58ChvBCelI and C58ChvBCelG by conjugation using pRK2013 as a mobilizing plasmid (Kovach et al. 1995).

The bacterial strains used in this study are listed in Table 2 .

\section{Attachment to roots and root colonization assays.}

Attachment of bacteria to tomato roots was measured as described previously (Matthysse 1987). Briefly, for microscopic assays, tomato root segments approximately $1 \mathrm{~cm}$ long suspended in $1 / 10$ Murashige-Skoog salts with $0.4 \%$ sucrose were inoculated with $10^{6}$ to $10^{7}$ bacteria/ $\mathrm{ml}$. These binding reactions contained an excess of bacteria for the amount of plant surface area available. Adherent cells were observed after 3, 7, 24, and $31 \mathrm{~h}$ using a Zeiss photoscope 2 and Nomarski optics. For viable cell count assays of bacterial attachment, the tomato root segments were inoculated with between $10^{3}$ and $10^{4}$ bacteria $/ \mathrm{ml}$. These binding assays provided an excess of plant sites for the number of bacteria available. Bound bacteria were released from the roots by sonication in $5 \mathrm{ml}$ of washing buffer (Loper et al. 1984) containing approximately $50 \mathrm{mg}$ of sterile quartz sand in a glassware cleaning bath sonicator for $2 \mathrm{~min}$. The resulting bacterial suspension then was plated to determine the number of viable cells that had been released. Root colonization was measured as previously described (Matthysse and McMahan 1998). For both root colonization and bacterial attachment measurements, bacterial colony morphology of celG and cell mutants was observed. Less than $1 \%$ of the colonies obtained showed altered colony morphology suggestive of failure to overproduce cellulose (smooth and fluid as opposed to rough and sticky). 


\section{Virulence.}

Bacterial virulence was determined by inoculating wounds on leaves of $B$. daigremontiana with approximately $10^{7}$ bacteria from a fresh plate of Luria agar with appropriate antibiotics. After inoculation, the plants were kept at room temperature and scored for tumor formation weekly for 6 weeks. The $\operatorname{chvB}$ mutation is temperature sensitive (Banta et al. 1998; Bash and Matthysse 2002); therefore, plants inoculated with the C58ChvB, C58ChvBCelG, and C58ChvBCelI strains were kept at the nonpermissive temperature of 25 to $27^{\circ} \mathrm{C}$. Inoculations with the parent strain C58, and C58CelI and C58CelG, resulted in the formation of tumors at all of the inoculated sites after 2 weeks.

\section{Preparation of extracts and measurement of cellulose synthesis by extracts.}

Bacteria to be used for the preparation of extracts were grown for 3 days in liquid medium on a roller drum as described previously. Extracts were prepared and the incorporation of UDP- ${ }^{14} \mathrm{C}$-glucose into cellulose was measured as previously described (Matthysse et al. 1995b). In order to determine the incorporation per bacterial cell, a viable cell count was done on the washed cells just prior to sonication so that the number of cells per milliliter of extract could be calculated. Measurements of incorporation of UDP- ${ }^{14} \mathrm{C}$-glucose into cellulose were made using varying amounts of extract and the incorporation per cell was calculated from the portion of the curve where the incorporation increased linearly with the amount of extract added.

\section{Preparation of dried pellets and chemical analysis.}

Bacteria were grown to stationary phase in Luria broth. The cells were collected by centrifugation at $10,000 \times g$ and washed two times with water, followed by resuspension in 1 to $10 \mathrm{ml}$ of water, and the number of viable cells was determined by plating on Luria agar. The pellets were dried under vacuum, weighed, and used for linkage analysis or for determination of chemical contents. The amount of cellulose was determined using the trifluoroacetic acid extraction procedure as described by Brown and associates (1976). Briefly, the cell pellet was suspended in $50 \mathrm{mM}$ Tris $\mathrm{HCl}$ buffer, $\mathrm{pH} 7.5$, and digested sequentially with lysozyme $(1 \mathrm{mg} / \mathrm{ml})$, DNAse $(0.1 \mathrm{mg} / \mathrm{ml})$, and proteinase $\mathrm{K}(1 \mathrm{mg} / \mathrm{ml})$. The insoluble material was pelleted at $5,000 \times g$, washed with water three times, and digested with $0.5 \mathrm{M} \mathrm{NaOH}$ containing $0.05 \mathrm{M} \mathrm{NaBH}_{4}$ at $65^{\circ} \mathrm{C}$. The remaining insoluble material was pelleted and the pellet was washed with water and $95 \%$ ethanol. The insoluble material was extracted with $0.5 \mathrm{~N}$ trifluoroacetic acid at $37^{\circ} \mathrm{C}$ for $3 \mathrm{~h}$, and the pellet was washed extensively with water, ethanol, and ether, dried, and weighed.

\section{PMAA.}

The dried cell pellets were derivatized for glycosyl linkage analysis by methylation with $n$-butyllithium (Carpita and Shea 1989; Valent et al. 1980; White et al. 1993a,b; York et al. 1985). Reaction products were dissolved in $0.5 \mathrm{ml}$ of dimethyl sulfoxide and $n$-butyllithium was added slowly, followed by methyl iodide. Methylated samples were extracted with chloroform and washed with water, and the chloroform phase was evaporated to dryness. Samples were fully hydrolyzed with $2 \mathrm{M}$ trifluoroacetic acid at $121^{\circ} \mathrm{C}$ for $1 \mathrm{~h}$ and reduced with $\mathrm{NaBD}_{4}$. Per-O-methylated alditols were acetylated with acetic anhydride and 1-methylimidazole as a catalyst (Blakeney et al. 1983).

\section{GC-MS linkage analysis.}

PMAAs were introduced by a 3-min splitless injection on a $30-\mathrm{m}$ by $0.75-\mathrm{mm}$ SP-2330 fused silica capillary column
(Supelco, Bellefonte, PA, U.S.A.) at a temperature of $170^{\circ} \mathrm{C}$. After a 3-min delay, column temperature was raised $4^{\circ} \mathrm{C} / \mathrm{min}$ to $240^{\circ} \mathrm{C}$, and derivative structures were deduced as described by Carpita and Shea (1989).

\section{ACKNOWLEDGMENTS}

This research was supported by the following grants: Department of Energy grant DE-FG03-00ER-15073 and grant DE-FG03-00ER-15074, and United States Department of Agriculture grant USDA-CRI 200235319-12636. We thank S. Slater for pointing out the existence of the celG open reading frame, S. Whitfield for assistance with photography and graphical work, and D. Cavalier for helpful reading of the results and discussion sections.

\section{LITERATURE CITED}

Banta, L. M., Bohme, J., Lovejoy, S. D., and Dostal, K. 1998. Stability of the Agrobacterium tumefaciens VirB10 protein is modulated by growth temperature and periplasmic osmoadaptation. J. Bacteriol. 180:65976606.

Bash, R., and Matthysse, A. G. 2002. Attachment to roots and virulence of a chvB mutant of Agrobacterium tumefaciens are temperature sensitive. Mol. Plant-Microbe Interact. 15:160-163.

Blakeney, A. B., Harris, P. J., Henry, R. J., and Stone, B. A. 1983. A simple and rapid preparation of alditol acetates for monosaccharide analysis. Carbohydr. Res. 113:291-299.

Brown, R. M., Jr., Willison, J. H. M., and Richardson, C. L. 1976. Cellulose biosynthesis in Acetobacter xylinum: visualization of the site of synthesis and direct measurement of the in vivo process. Proc. Natl. Acad. Sci. U.S.A. 73:4565-4569.

Cannon, R. E., and Anderson, S. M. 1991. Biogenesis of bacterial cellulose. Crit. Rev. Microbiol. 17:435-447.

Carpita, N. C., and Shea, E. M. 1989. Linkage structure of carbohydrates by gc-ms of partially methylated alditol acetates. Pages 157-216 in: Analysis of Carbohydrates by GLC and M-S. C. J. Biermann and G. D. McGinnis, eds. CRC Press, Boca Raton, FL, U.S.A.

Douglas, C. J., Halperin, W., and Nester, E. W. 1982. Agrobacterium tumefaciens mutants affected in attachment to plants. J. Bacteriol. 152:12651275.

Hentzer, M., Teitzel, G. M., Balzer, G. J., Heydorn, A., Molin, S., Givskov, M., and Parsek, M. R. 2001. Alginate overproduction affects Pseudomonas aeruginosa biofilm structure and function. J. Bacteriol. 183:5395-5401.

Kovach, M. E., Elzer, P. H., Hill, D. S., Robertson, G. T. Farris, M. A., Roop, R. M., and Peterson, K. M. 1995. Four new derivatives of the broad-host-range cloning vector pBBR1MCS, carrying different antibiotic-resistance cassettes. Gene 166:175-176.

Loper, J. E., Suslow, T. V, and Schroth, M. N. 1984. Lognormal distribution of bacterial populations in the rhizosphere. Phytopathology 74:1454-1460.

Mathee, K., Ciofu, O., Sternberg, C., Lindum, P. W., Campbell, J. I., Jensen, P., Johnsen, A. H., Givskov, M., Ohman, D. E., Molin, S., Hoiby, N., and Kharazmi, A. 1999. Mucoid conversion of Pseudomonas aeruginosa by hydrogen peroxide: a mechanism for virulence activation in the cystic fibrosis lung. Microbiology 145:1349-1357.

Matthysse, A. G. 1983. Role of bacterial cellulose fibrils in Agrobacterium tumefaciens infection. J. Bacteriol. 154:906-915.

Matthysse, A. G. 1987. Characterization of nonattaching mutants of Agrobacterium tumefaciens. J. Bacteriol. 169:313-323.

Matthysse, A. G., Holmes, K. V., and Gurlitz, R. H. 1981. Elaboration of cellulose fibrils by Agrobacterium tumefaciens during attachment to carrot cells. J. Bacteriol. 145:583-595.

Matthysse, A. G., Lightfoot, R., and White, S. 1995a. Genes required for cellulose synthesis in Agrobacterium tumefaciens. J. Bacteriol. 177:1069-1075.

Matthysse, A. G., Thomas, D. L., and White, A. R. 1995b. Mechanism of cellulose synthesis in Agrobacterium tumefaciens. J. Bacteriol. 177:1076-1081.

Matthysse, A. G.., and McMahan, S. 1998. Root colonization by Agrobacterium tumefaciens is reduced in $\mathrm{cel}$, attB, attD, and attR mutants. Appl. Environ. Microbiol. 64:2341-2345.

Matthysse, A. G., Deschet, K., Williams, M., Marry, M., White, A. R., and Smith, W. C. 2004. A functional cellulose synthase from ascidian epidermis. Proc. Natl. Acad. Sci. U.S.A. 101:986-991.

Minnemeyer, S. L., Lightfoot, R., and Matthysse, A. G. 1991. A semiquantitative bioassay for relative virulence of Agrobacterium tumefaciens strains on Bryophyllum daigremontiana. J. Bacteriol.173:7723-7724. 
Parsek, M. R., and Fuqua, C. 2004. Biofilms 2003: emerging themes and challenges in studies of surface-associated microbial life. J. Bacteriol. 186:4427-40.

Puvanesarajah, V., Schell, F. M., Stacey, G., Douglas, C. J., and Nester, E. W. 1985. Role for 2-linked-beta-D-glucan in the virulence of Agrobacterium tumefaciens. J. Bacteriol. 164:102-106.

Ramey, B. E., Matthysse, A. G., and Fuqua, C. 2004. The FNR-type transcriptional regulator SinR controls maturation of Agrobacterium tumefaciens biofilms. Mol. Microbiol. 52:1495-1511.

Spiers, A. J., Bohannon, J., Gehrig, S. M., and Rainey, P. B. 2003. Biofilm formation at the air-liquid interface by the Pseudomonas fluorescens SBW25 wrinkly spreader requires an acetylated form of cellulose. Mol. Microbiol. 50:15-27.

Sutherland, I. W. 2001. Biofilm exopolysaccharides: a strong and sticky framework. Microbiology 147:3-9.

Valent, B. S., Darvill, A. G., McNeil, M., Robertsen, B. K., and Albersheim, P. 1980. A general and sensitive chemical method for sequencing the glycosyl residues of complex carbohydrates. Carbohydr. Res. 79:165-192.

White, A. P., Gibson, D. L., Collinson, S. K., Banser, P. A., and Kay, W. W.
2003. Extracellular polysaccharides associated with thin aggregative fimbriae of Salmonella enterica serovar enteritidis. J. Bacteriol. 185:5398-5407.

White, A. R., Xin, Y., and Pezeshk, P. 1993a. Separation of membranes from semiprotoplasts of suspension-cultured sycamore maple (Acer pseudoplatanus) cells. Physiol. Plantarum 87:31-38.

White, A. R., Xin, Y., and Pezeshk, P. 1993b. Xyloglucan synthase in Golgi membranes from Pisum sativum. Biochem. J. 294:231-238.

Yildiz, F. H., and Schoolnik, G. K. 1999. Vibrio cholerae 01 El Tor: Identification of a gene cluster required for the rugose colony type, exopolysaccharide production, chlorine resistance, and biofilm formation. Proc. Natl. Acad. Sci. U.S.A. 96:4028-4033.

York, W. S., Darvill, A. G., McNeil, M., Stevenson, T. T., and Albersheim, P. 1985. Isolation and characterization of plant cell walls and cell wall components. Methods Enzymol. 118:3-40.

Zogaj, X., Nimtz, M., Rohde, M., Bokranz, W., and Romling, U. 2001 The multicellular morphotypes of Salmonella typhimurium and Escherichia coli produce cellulose as the second component of the extracellular matrix. Mol. Microbiol. 39:1452-1463. 